INTERNATIONAL J OURNAL OF RESEARCH IN PHARMACY AND CHEMISTRY

\title{
KNOWLEDGE AND ATTITUDE OF PHARMACY STUDENTS TOWARDS PHARMACOVIGILANCE
}

\author{
G. Vijaya Kumar*, Chandra. Lakshmi Shirini, Chalasani. Sruthi, \\ Bonthu. Sanjana, Bollu. Divya Durga and Bokinala Subhash \\ Department of Pharmacy Practice, Kommareddy Venkata Sada \\ Siva Rao Siddhartha College of Pharmaceutical Sciences, \\ Vijayawada- 520 010, Andhra Pradesh, India.
}

\begin{abstract}
BACKGROUND: The main role of pharmacovigilance is the early detection of adverse drug reactions ADR"s and reporting the problems associated with them. This study was conducted to evaluate the knowledge and attitude of pharmacy students towards Pharmacovigilance among the students of both graduate and undergraduate. Methods: A cross sectional study was conducted among pharmacy students of both public and private universities in and around Vijaywada. The survey form comprises two sections each of 8 questions, the responses were taken and analysed using MS Excel software. Result: In this cross-sectional study, 300 knowledge and attitude questionnaires are distributed, about 296 pharmacy students gave their responses to the questionnaire in which majority of students are females with a sum of 226 and males are about 70. According to our study there is positive results towards knowledge of students regarding pharmacovigilance. Conclusion: This study concludes that pharmacy students' knowledge towards pharmacovigilance and ADR reporting is commendable, whereas attitude was found to be inadequate. Hence there is necessity to create awareness about ADR's reporting among pharmacy students.
\end{abstract}

Keyw ords: Pharmacovigilance, Knowledge, Attitude and Adverse Drug Reaction.

\section{INTRODUCTION}

Adverse drug reactions are major causes of morbidity and mortality globally. ${ }^{1}$ World health organisation (WHO) has started the drug monitoring after the so- called Thalidomide disaster in the year 1961. The root cause of this program is to strengthen the drug safety by providing required data for the safe use of medicines and management of ADR's. ${ }^{2,3}$

According to World Health Organisation - Adverse drug reaction can be defined as any reaction to a drug which is poisonous and accidental, and which occurs at doses normally used in man for prevention, detection, treatment for a disease, or for the changes in the anatomical function." 4

ADR is one among the 10 causes for deaths. According to a study in the US alone, the estimated yearly cost due to drug induced mor- bidity and mortality in year 2016 was $\$ 528.4$ billion, which was nearly $16 \%$ of the total health care cost of that year. Thus to prevent and reduce ADR's measures for assessing and monitoring Drug safety are very pivotal. Whereas the scenario in India is records about $2.4 \%-6.5 \%$ of the admissions in the health centres are due to adverse reactions, many of which are curable. In India the occurrence of serious ADR's is around 6.7\%.

Pharmacovigilance (PV) is defined as "the science and research activities relating to the perception, evaluation, understanding and hindrance of adverse drug events or any other Drug associated problems."

It is an umbrella term used to describe the process for monitoring and evaluating ADR's. It is the study of marketed drugs examined 
under the practical conditions of clinical use in large populations. ${ }^{6}$

\section{ROLE OF PHARMACOVIGILANCE}

Drugs appear to be safe and very tolerated, but the safety in the "real world" is unclear for Chronically/ repeatedly use of drugs and use with other drugs. Safety in vulnerable groups such as pregnant women, breastfeeding mother, elderly, young children is unknown. Notable harm to a few patients, rumours and myths can destroy the creditability, adherence to and success of a treatment, It is also useful for

- Early detection of unknown safety problems,

- Detection of increases in frequency,

- Identification of risk factors,

- Quantifying the risks,

- Preventing patients from being affected unnecessarily.

The Pharmacovigilance program was started with a purpose of ensuring patient safety for people of India. ${ }^{7}$ In the year 2010 the Central Drug Standard Control Organisation (CDSCO),New Delhi has begin around a country-wide pharmacovigilance program sponsored by Ministry of health and Family Welfare, Government of India with All India Institute of Medical Sciences (AlIMS),New Delhi as a National Coordinating Centre(NCC) to manage ADR's. Hence facilitated successful way to execution of this program, NCC transfer from AlIMS, New Delhi to the Indian Pharmacopoeia Commission, Ghaziabad in April, 2011 under aegis of Uppsala Monitoring Centre - World Health Organisation ( UMC WHO). The (UMC- WHO),Sweden is controlling the Worldwide database of ADR reports received from various National Pharmacovigilance centres of individual countries. ${ }^{8}$

In present-day situations, the role of pharmacists in control of ADR's and medication errors as well as in pharmacovigilance has substantially enhanced patients compliance and also attributes to the overall quality of life of patients. Nonetheless there are still some drawbacks exist in reporting ADR'S. Some of the barriers include lack of knowledge and training on pharmacovigilance and also attitude of pharmacists towards ADR reporting.

Pharmacy students are considered as the upcoming healthcare professionals of their countries. In India, majority of the pharmacy students degree holders from private and public universities, where there exists a difference in quality of education. Hence, pharmacy students from both public and private universities must be well trained to identify and report ADR's.

Therefore, the main intent of this study is to evaluate the knowledge and attitude of the students towards pharmacovigilance and ADR reporting in colleges situated in Guntur and Krishna District of Andhra Pradesh.

\section{MATERIALS AND METHODS}

A Cross sectional study was conducted through distributing a questionnaire among the students of both under graduate (final year Bpharmacy) and graduate pharmacy students (M- pharmacy) from the public and private universities of Guntur and Krishna district of AP. By considering the relevant knowledge and attitude of students towards pharmacovigilance and ADR reporting a questionnaire was prepared. The survey form comprises of two sections each of 8 questions, in which first section deals with knowledge of students where as, the second section related to attitude of students towards PV and ADR reporting.

And as this study requires the involvement of students in the form of responses so the required permission was obtained from head of the institutions. The students were instructed to give responses for the given questionnaire which is delivered to them by hand. After collecting the responses from the students, in order to create awareness a testimonial is provided to the students. The required data is recorded and analysed.

\section{RESULTS AND DISCUSSION}

In this cross-sectional study, 300knowledge and attitude questionnaires are distributed, about 296 pharmacy students gave their responses to the questionnaire in which majority of students are females with a sum of 226 and males are about 70 . The statistical analysis is done by noting down the responses from the returned questionnaire and data were analysed using MS excel software.

Table 1 AND 2: Knowledge of pharmacy students towards pharmacovigilance and ADR reporting

Q1- Do you have any idea regarding Pharmacovigilance?

Q2- Can you define ADR and give some examples?

Q3- Do you have any idea about the yellow card?

Q4- Do you have any idea regarding ADR monitoring centers in AP?

Q5- Would you report ADR'S to all the health care professionals?

Q6- Are you aware of any drugs that are banned recently due to adverse drug reactions?

Q7- Do you agree that GIT and nervous system are the organs most affected by ADR'S? 
Q8- Do you have any idea about role of pharmacists in preventing ADR'S?

The findings in the knowledge questionnaire shows, majority $(80.74 \%)$ of students gave correct response for the definition of pharmacovigilance,(90.87\%) are able to define ADR and can also state few examples of ADR, and most of students not aware of yellow card (89.86\%) and also ADR monitoring center's in AP which is $(75.67 \%)$ and about $(56.08 \%)$ of students believed that ADR's should be reported to all the health care professionals, $(59.79 \%)$ are aware of drugs that are banned due to ADR'S.

And 3/4th of the respondents agreed that GIT and nervous system are most effected by ADR's and also have idea regarding role of pharmacists in preventing ADR's (82.09\%, $87.50 \%)$.

TABLE 3 AND 4: Attitude of Pharmacy students Towards Pharmacovigilance and ADR reporting analysis of observed yes responses

Q1-Do you think reporting an ADR is necessary?

Q2-Have you ever seen an ADR reporting form?

Q3-With your present knowledge are you able to report any ADR'S?

Q4-Do you think pharmacovigilance should be thought in detail to healthcare professionals?

Q5-Have you ever read any article on prevention of ADR'S?

Q6-Is there any pharmacovigilance committee in your institute?

Q7-Can a non medical person report ADR to a nearby healthcare professional?

Q8-Is there a need to include pharmacovigilance in undergraduate curriculum to create awareness among the budding doctors

The findings in the attitude questionnaire shows, nearly 95\% students think that reporting an ADR is necessary. It is also revealed that $(74.66 \%)$ of them have not seen an ADR reporting form. With their present knowledge $(61.48 \%)$ are able to report some of the ADR'S. Majority (82.77\%) of the students believe that pharmacovigilance should be taught in detail to healthcare professionals. Besides more than half of them $(70.27 \%)$ haven't read any article on prevention of ADR'S and also most of the institutes doesn't have any pharmacovigilance committee $(80.74 \%)$, (59.45\%) of respondents believe that a non-medical person can report
ADR to a nearby healthcare professional. Approximately all the students $(90.20 \%)$ think there is need to include pharmacovigilance in under graduate curriculum.

Pharmacovigilance is an essential part of the comprehensive healthcare system. In order to improve patients care and safety it is necessary to create awareness about PV and spontaneous reporting of ADR's. After the keen observation, our study shows positive results towards knowledge whereas attitude of the students is poor as compared to knowledge.

According to our study there is positive results towards knowledge of students regarding pharmacovigilance. When compared with KAP about PV: a cross sectional study involving pharmacy students of selected universities in Bangladesh their results shows that, there is inadequate knowledge but positive attitude. ${ }^{9}$

Several studies suggest that less reporting of ADR's is concerned with two factors mainly: knowledge and attitude of health care professionals, presence of a functioning ADR reporting frame work.

For the successful execution of Pharmacovigilance, the ADR reporting culture among the healthcare professionals should be promoted. Education is the important tool which contributes to the development of a country. ${ }^{10}$

So, in order to educate the pharmacy students and enhance their KAP towards ADR's and $\mathrm{PV}$, the curriculum at the undergraduate and postgraduate masters' program needs to be improved. Thus this will enhance the united healthcare system by creating peer group of well educated and trained pharmacy professionals.

\section{CONCLUSION}

This study concludes that pharmacy students' knowledge towards pharmacovigilance and ADR reporting is commendable, whereas attitude was found to be inadequate. Hence it is recommended from the study that there is need to create awareness about ADR reporting among the pharmacy students to ensure a safe health and prevention of ADR'S in future.

\section{ACKNOWLEDGMENT}

We would like to express our sincere gratitude to Dr. Devala Rao Garikapati, professor \& principal, Dr. CH. Nageshwara Rao, convener of our institute and Sri. P. Lakshmana Rao Secretary of Siddhartha Academy of General and Technical Education, Vijayawada, Who provided departmental facilities and helped us whenever required. 
Table 1: Knowledge of pharmacy students towards pharmacovigilance and ADR reporting analysis of observed yes responses

\begin{tabular}{|c|c|c|c|c|c|}
\hline Question & observed (yes) & expected (yes) & $\begin{array}{c}\text { observed - expected } \\
\text { (O-E) }\end{array}$ & $\begin{array}{c}\text { (observed - expected)2 } \\
\text { (O-E)2 }\end{array}$ & 3262.694 \\
\hline Q1 & 239 & 181.88 & 57.12 & 7589.894 & 17.94 \\
\hline Q2 & 269 & 181.88 & 87.12 & 23067.534 & 12.073 \\
\hline Q3 & 30 & 181.88 & -151.88 & 252.174 \\
\hline Q4 & 72 & 181.88 & -109.88 & 23.814 \\
\hline Q5 & 166 & 181.88 & -15.88 & 1.38 \\
\hline Q6 & 177 & 181.88 & -4.88 & 3735.654 \\
\hline Q7 & 243 & 181.88 & 61.12 & 5.13 \\
\hline Q8 & & & 77.12 & 594.494 \\
\hline
\end{tabular}

\section{KNOWLEDGE OF PHARMACY STUDENTS REGARDING PHARMACOVIGILANCE AND ADR}

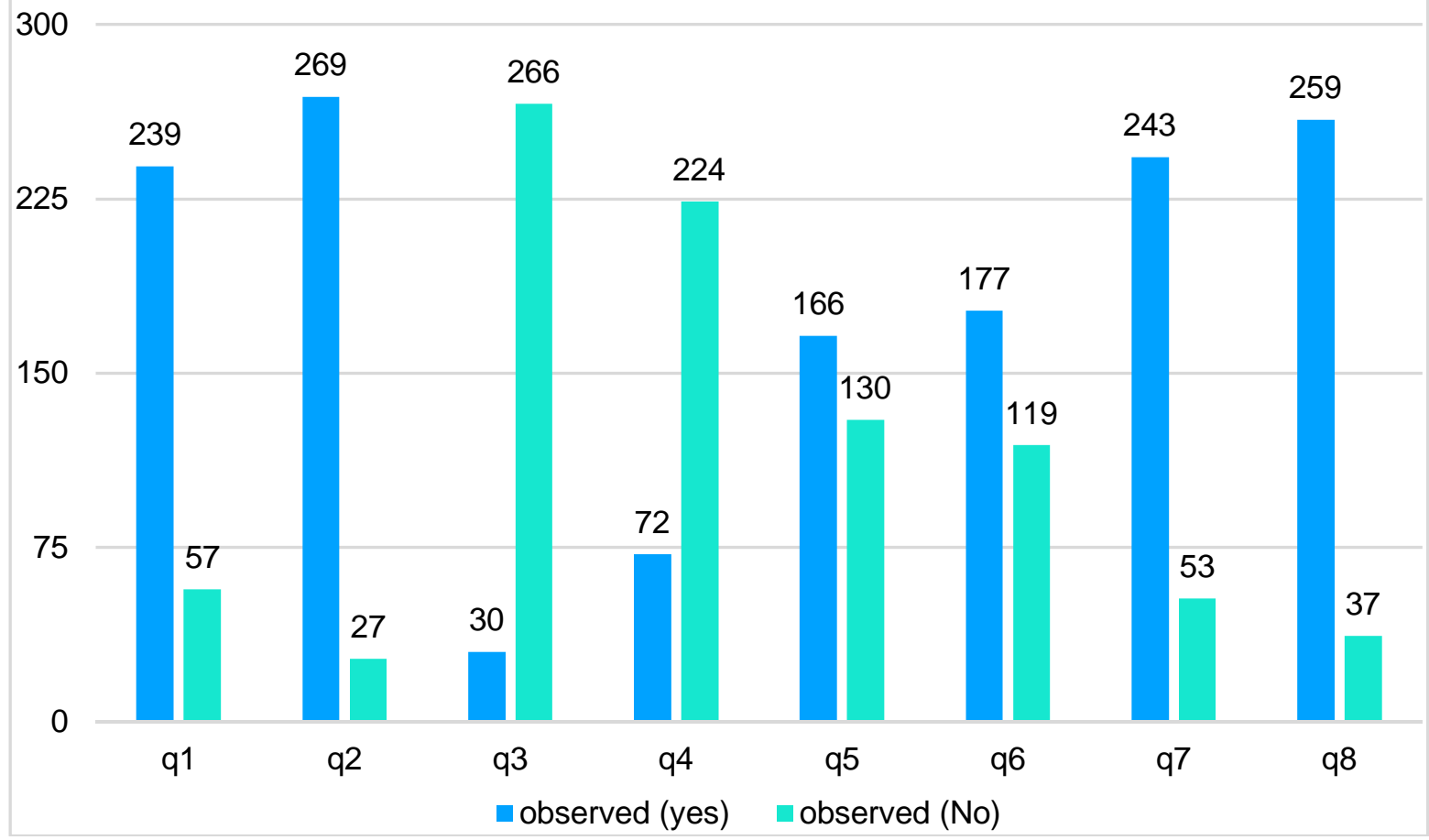

Fig. 1: Knowledge of Pharmacy students towards pharmacovigilance and ADR reporting

Table 2: Knowledge of pharmacy students towards pharmacovigilance 
and ADR reporting analysis of observed no responses

\begin{tabular}{|c|c|c|c|c|c|}
\hline Question & observed (No) & expected (no) & $\begin{array}{c}\text { observed - expected } \\
(\mathbf{O}-\mathrm{E})\end{array}$ & $\begin{array}{c}\text { (observed - expected) } \\
(\mathbf{O}-\mathrm{E})^{2}\end{array}$ & chi square $^{\mathbf{2}}$ \\
\hline Q1 & 57 & 114.13 & 57.13 & 3263.83 & 28.597 \\
\hline Q2 & 27 & 114.13 & 87.13 & 7591.636 & 66.418 \\
\hline Q3 & 266 & 114.13 & 151.87 & 23064.496 & 202.08 \\
\hline Q4 & 224 & 114.13 & 109.87 & 12071.416 & 105.76 \\
\hline Q5 & 130 & 114.13 & 15.87 & 251.856 & 2.2 \\
\hline Q6 & 119 & 114.13 & 4.87 & 23.716 & 0.207 \\
\hline Q7 & 53 & 114.13 & 61.13 & 6736.876 & 32.74 \\
\hline Q8 & 37 & 114.13 & 77.13 & 5949.036 & 52.12 \\
\hline & & & & Total & 61.26 \\
\hline
\end{tabular}

Table 3: Attitude of Pharmacy Students towards pharmacovigilance and ADR reporting analysis of observed yes responses

\begin{tabular}{|c|c|c|c|c|c|}
\hline Question & observed (yes) & expected (yes) & $\begin{array}{c}\text { observed - expected } \\
\text { (O-E) }\end{array}$ & $\begin{array}{c}\text { (observed - expected)2 } \\
\text { (O-E)2 }\end{array}$ & chi square \\
\hline Q1 & 283 & 171.63 & 111.37 & 12403.276 & 72.26 \\
\hline Q2 & 75 & 171.63 & 96.63 & 9337.356 & 54.4 \\
\hline Q3 & 182 & 171.63 & 10.37 & 107.536 & 0.626 \\
\hline Q4 & 245 & 171.63 & 73.37 & 5383.156 & 31.36 \\
\hline Q5 & 88 & 171.63 & 83.63 & 6993.976 & 40.75 \\
\hline Q6 & 57 & 171.63 & 114.63 & 13140.036 & 76.56 \\
\hline Q7 & 176 & 171.63 & 4.37 & 19.096 & 0.111 \\
\hline Q8 & 267 & 171.63 & 95.37 & 9095.436 & 25.99 \\
\hline & & & & Total & 41.13 \\
\hline
\end{tabular}

Table 4: Attitude of pharmacy students towards pharmacovigilance and ADR reporting analysis of observed no responses

\begin{tabular}{|c|c|c|c|c|c|}
\hline Question & observed (No) & expected (No) & $\begin{array}{c}\text { observed - expected } \\
\text { (O-E) }\end{array}$ & $\begin{array}{c}\text { (observed - expected)2 } \\
\text { (O-E)2 }\end{array}$ & chi square \\
\hline Q1 & 13 & 124.38 & 111.38 & 12405.504 & 99.73 \\
\hline Q2 & 221 & 124.38 & 96.62 & 9335.424 & 75.05 \\
\hline Q3 & 114 & 124.38 & 10.38 & 107.744 & 0.866 \\
\hline Q4 & 51 & 124.38 & 73.38 & 5384.624 & 43.29 \\
\hline Q5 & 208 & 124.38 & 83.62 & 6992.304 & 56.21 \\
\hline Q6 & 239 & 124.38 & 114.62 & 13137.744 & 105.62 \\
\hline Q7 & 120 & 124.38 & 4.38 & 19.184 & 0.15 \\
\hline Q8 & 29 & 124.38 & 95.38 & 9097.344 & 73.14 \\
\hline & & & & Total & 56.76 \\
\hline
\end{tabular}




\section{ATTITUDE OF PHARMACY STUDENTS REGARDING PHARMACOVIGILANCE AND ADR}

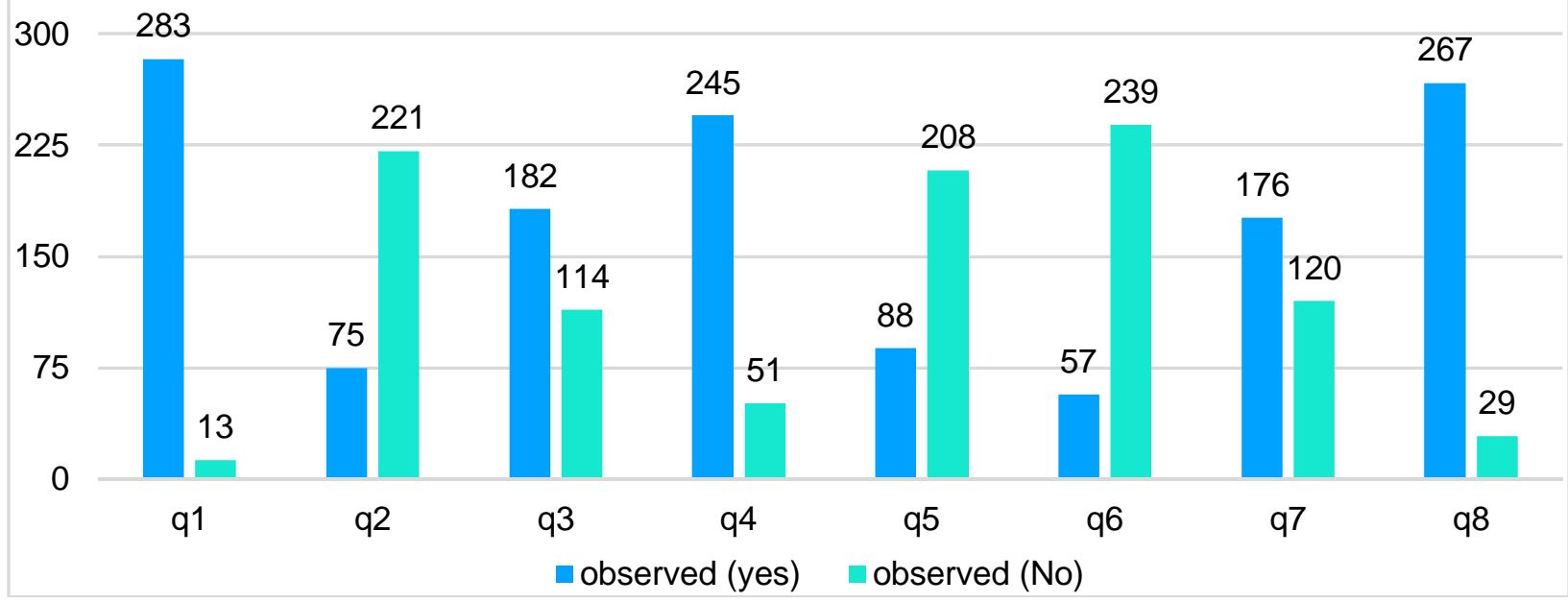

Fig. 2: Attitude of Pharmacy students towards pharmacovigilance and ADR reporting analysis of observed no responses

\section{REFERENCES}

1. Shashi Marko. A study of knowledge, attitude and practice of pharmacovigilance among medical students at a tertiary care teaching hospital in Madhya Pradesh, India, National journal of physiology, Pharmacy and pharmacology. 2019;9:851-855.

2. Shamim S, Sharib SM, Malhi SM, Muntaha SU, Raza H and Ata S. Adverse drug reactions (ADRS) reporting: awareness and reasons of under- reporting among healthcare professionals, a challenge for pharmacists. Springerp Plus. 2016;1;5(1):1778.

3. Shamim S, Sharib SM, Malhi SM, Muntaha SU, Raza H and Ata S. Adverse drug reactions (ADRS) reporting: awareness and reasons of under- reporting among healthcare professionals, a challenge for pharmacists. Springerp Plus. 2016;5(1):1778

4. Parthasarathi G, Karin Nyfort, Hansen, Milap C Nahata. A Textbook of Clinical Pharmacy Practice- Essential Concepts and Skills. 2019.

5. Fatemah M Alsaleh, Sherifah W Alzaid, Eman A. Abahussain, Tania Bayoud and Jacinthe Lemacy. Knowledge, attitude and practice of pharmacovigilance and adverse drug reactions reporting among pharmacists working in secondary and tertiary government hospitals in Kuwait. Saudi pharmaceutical Journal. 2017;832837.

6. WHO policy perspectives on Medicines, pharmacovigilance: Ensuring the Safe use of Medicines, Geneva: World Health Organization. 2004. Available from: http://ww.apps.who.int/medicinedocs/pdf/s 6164e/s6164e.

7. Ramya, History and Evolution of Pharmacovigilance, June, 2019, Available from: https://allaboutpharmacovigilance.org/hist ory-and-evolution-of-pharmacovigilance.

8. Het B Upadhyaya, Mukesh Kumar B Vora , Jatin G Nagar and Pruthvish B. Patel, Knowledge, attitude and practice of pharmacovigilance and adverse drug reactions in post graduate students of Tertiary Care Hospital in Gujarat, Journal of Advanced Pharmaceutical Technology and Research. 2015;6(1):29-34.

9. Sharmind Neelotpol, Marzia Alam, Syeda Fahria Hoque Mimmi and Md Hamza Albee. Knowledge and Attitude about Pharmacovigilance A Cross-sectional study involving pharmacy students of selected universities in Bangladesh. Journal of Pharmacovigilance. 2020;8:289. 